\title{
Open
}

\section{Factors associated with knowledge of and satisfaction with newborn screening education: a survey of mothers}

\author{
Makda H. Araia, MSc'1, Brenda J. Wilson, FFPH ${ }^{1}$, Pranesh Chakraborty, MD, FRCPC ${ }^{2,3}$, \\ Kimberly Gall, $\mathrm{MSc}^{2,3}$, Christina Honeywell, $\mathrm{MSc}^{4}$, Jennifer Milburn, MHA ${ }^{2}$, Tim Ramsay, PhD ${ }^{1,5}$, \\ and Beth K. Potter, PhD ${ }^{1}$
}

\begin{abstract}
Purpose: Effective parental education about newborn blood-spot screening may facilitate prompt follow-up, reduce psychosocial harms, and promote trust in screening programs. However, little is known about the aspects of education delivery and content that are of most importance for fostering understanding and meeting parental expectations. We aimed to identify elements of newborn blood-spot screening education and their associations with mothers' knowledge and satisfaction levels.
\end{abstract}

Methods: We conducted a survey (by mail) of 1,712 mothers who were residing in Ontario, Canada, and whose infants had recently undergone newborn blood-spot screening.

Results: We received 750 completed questionnaires (response rate $47 \%)$. Factors associated with respondents' higher knowledge of newborn blood-spot screening were higher level of education (odds ratio $=2.79$ ), English being spoken at home (odds ratio $=1.96$ ), receiving an information sheet at the time of newborn blood-spot screening (odds ratio $=1.57$ ), and receiving information about how

\section{INTRODUCTION}

Population-based newborn blood-spot screening (NBS) aims to identify infants with rare but treatable health conditions for which early intervention is expected to lead to improved outcomes. Although pre-screening education for parents is recognized as an integral part of NBS programs, existing evidence suggests that parents often receive little information about NBS and many even remain unaware that their baby has been screened. ${ }^{1,2}$ One potential reason for this limited pre-screening education is that, in many jurisdictions, NBS is either mandatory (e.g., most US states) or considered to be the standard of care for newborns (e.g., most Canadian provinces). Without a perceived need to provide information as a component of explicit informed consent, education about NBS may not be systematically integrated into maternal newborn care. A further explanation for the low intensity of education is that NBS occurs early in the postpartum period. For example, in Canada, the blood spot sample is usually collected $24-72 \mathrm{~h}$ after birth, which is typically before the mother and infant are discharged from the hospital. This is a vulnerable time in a new parent's life-when many health-care decisions are being made, both mother and infant are recovering to interpret the results (odds ratio $=2.65$ ). Factors associated with being satisfied were: receiving information prenatally (odds ratio = 2.35 ), from a health-care professional (odds ratio $=4.54$ ), or from an information sheet at the time of newborn blood-spot screening (odds ratio $=1.72$ ); and receiving messages about the purpose of screening (odds ratio $=3.78$ ), the communication process (odds ratio $=2.57$ ), the interpretation of the results (odds ratio $=4.19$ ), and sample-handling methods (odds ratio $=3.13$ ).

Conclusion: Promoting mothers' understanding and meeting their expectations with respect to education about newborn blood-spot screening may require greater engagement with prenatal providers. It also calls for a greater emphasis on communicating with mothers about how blood samples are handled and about the meaning of the test results.

Genet Med 2012:14(12):963-970

Key Words: education; genetic screening; newborn screening; public health genomics

from the birth, and there are competing educational priorities even in the absence of specific health concerns. The fact that this immediate postnatal period may not be the best time for NBS education is recognized by both parents and professionals, who have expressed a preference for education about NBS to be carried out during pregnancy. ${ }^{1,3-6}$ However, there is evidence that some prenatal care providers feel unprepared to educate prospective parents about NBS and/or may not see this as part of their role. $^{7}$

Despite these barriers, there are important reasons for providing effective pre-screening education about NBS to parents and/or prospective parents. For example, it has been proposed that such efforts are important for achieving the primary goals of NBS: if parents are aware of the benefits, purpose, and process of screening, they may be more likely to respond promptly to requests for additional testing after a positive (abnormal) result or unsatisfactory sample. ${ }^{8}$ Effective education may also help to mitigate psychosocial harms; for instance, by informing parents, before testing, that an initial positive result is a possibility and does not represent a confirmatory diagnosis, it may be possible to reduce the risk of psychosocial harm associated with receiving a false-positive NBS result., ${ }^{910}$ This is highly relevant

${ }^{1}$ Department of Epidemiology \& Community Medicine, University of Ottawa, Ottawa, Ontario, Canada; ${ }^{2}$ Newborn Screening Ontario, Children's Hospital of Eastern Ontario, Ottawa, Ontario, Canada; ${ }^{3}$ Department of Pediatrics, University of Ottawa, Ottawa, Ontario, Canada; ${ }^{4}$ Department of Genetics, Children's Hospital of Eastern Ontario, Ottawa, Ontario, Canada; ${ }^{5}$ The Ottawa Hospital Research Institute, Ottawa, Ontario, Canada. Correspondence: Beth K. Potter (bpotter@uottawa.ca) 
in the context of continued expansion of NBS programs, which will inevitably lead to an increase in the number of false-positive results. Education that meets parental expectations for being informed may help to promote trust in NBS as a public health program. The importance of transparent communication as a way to protect public/parental trust in public health programs should not be underestimated, as demonstrated by recent legal and policy debates about the retention and secondary research use of NBS blood samples, ${ }^{11-13}$ and discussions regarding public confidence in vaccination programs. ${ }^{14}$

Several guidelines have been developed to inform NBS programs' educational initiatives, ${ }^{15-17}$ which, in some cases ${ }^{1,18}$ were informed by qualitative research exploring parents' and professionals' views and experiences. However, little is known about the specific aspects of education that are most important for fostering an understanding of NBS among parents in general, and also about how parents themselves view the education they receive. This survey of a representative sample of mothers in Ontario, Canada, was designed to identify the elements of pre-screening education (what, who, and how) that are most strongly associated with their knowledge and satisfaction regarding NBS.

\section{Sample and data collection methods \\ MATERIALS AND METHODS}

A simple random sample of 1,712 mothers whose infants had participated in NBS in Ontario within the previous 6 months were invited to complete a mailed survey about NBS education. We chose to sample only mothers whose infants received negative screening results because we were interested in experiences with pre-screening education and information; parents of infants with positive results would have received considerable post-screening information, which we believed would be challenging to distinguish from the pre-screening experience. Following Dillman's tailored design method, ${ }^{19}$ all potential participants received a pre-notification letter about the study; a package of information that contained a copy of the questionnaire to be completed and a small incentive (a $\$ 2$ coffee shop gift card); and a reminder postcard. The remaining nonresponders received up to two more mailings that included further copies of the questionnaire. The participants were asked to return completed questionnaires by mail or to respond online through a secure server with a unique username and password. They were given the option to respond in either English or French. This study received approval from the Children's Hospital of Eastern Ontario Research Ethics Board.

Questionnaire and measures of knowledge and satisfaction Guided by a review of the literature, we developed a new questionnaire for the study, reviewing and refining it in multiple rounds of discussion among team members with expertise in newborn screening, public health, genetic counseling, pediatrics, and survey research methods. The questionnaire was pre-tested among a small group of pregnant women recruited through prenatal classes at the Ottawa Hospital (with approval from the Ottawa Hospital Research Ethics Board). After minor revisions based on the pre-test findings, the final version of the questionnaire consisted of five sections designed to obtain information regarding participants': (i) experiences with education about pregnancy, childbirth, and newborn care generally; (ii) experiences with NBS education specifically (e.g., the timing, source(s), and method(s) of communicating the information, as well as the actual content of the information); (iii) opinions about NBS education (timing, source(s), method(s), and messages) that mothers believed would be most effective; (iv) knowledge of the content of particular educational messages; and (v) demographic characteristics.

In order to ascertain the extent to which the respondents understood the educational messages, they were asked a series of five questions in multiple choice or true/false formats. These questions were chosen on the basis of existing guidance for parental education about NBS, ${ }^{1}$ and to focus on information (the purpose and process of screening and the possibility of a false-positive result) that is believed to be important for parents to know so as to maximize the benefits of screening and mitigate potential harms. We also incorporated a question regarding parental choice/consent. Parents may opt out of NBS in Ontario, but screening occurs in most maternity hospitals by default unless there is a specific objection by parents. Therefore, we believed that a question assessing whether the respondents were aware of the nonmandatory nature of NBS might distinguish between those who had received specific education about NBS and those who had not. We assessed the participants' extent of knowledge in five specific areas of NBS education: (i) the main purpose of NBS (to identify infants who may have a rare disease so that treatment can begin right away so as to prevent serious health problems); (ii) the timing of screening (for greater accuracy, the blood sample is collected after $24 \mathrm{~h}$ of age); (iii) the process of communicating test results (parents are contacted by a health-care provider if the NBS test results are positive); (iv) the possibility of false-positive results (there may be a positive/abnormal NBS test result even if the infant does not have a disease); and (v) consent (parents have the right to choose not to have their infant tested).

To identify whether mothers' expectations about education had been met, the respondents who reported that they recalled receiving information about NBS were also asked to indicate their level of satisfaction (on a five-point scale, from "very satisfied" to "very dissatisfied") with the information they received.

\section{Data analysis}

Analyses were carried out using SAS version 9.1 (SAS Institute, Cary, NC). After carrying out descriptive analysis, we investigated predictors of "high" knowledge and being "satisfied" as dichotomous outcomes, using logistic regression analysis. For this purpose, "high knowledge" was defined as having responded correctly to at least four of the five knowledge questions; responses of "don't know" were grouped with incorrect responses. Participants were considered to have been satisfied if they indicated that they were "very" or "somewhat" satisfied 
with the information they received. In bivariate analysis, potential predictors of high knowledge and of satisfaction included receipt of any information about NBS (as a predictor of knowledge), details of experiences with NBS education (e.g., recollection of particular messages, source, and timing of education) and participant characteristics (e.g., age, education, language, and parity). Multiple logistic regression analysis with automated backwards elimination was then used to identify the predictors most strongly associated with high knowledge and with satisfaction. Because the knowledge questions were asked of all the participants, two multivariable models were developed for knowledge: one model for all participants (which included "recall of receipt of any information about NBS" as a predictor) and one for participants who recalled receiving information about NBS (which included details about participants' recalled experiences with NBS education as predictors). Satisfaction with education was ascertained only among participants who recalled receiving education, and therefore only one multivariable model was constructed for this outcome.

\section{RESULTS}

\section{Response rate and sample characteristics}

From our initial sample of 1,712 potential participants, we received 750 completed questionnaires, yielding a response rate of $47 \%$ (750/1,582, after excluding 128 participants with incorrect addresses and 2 who were found to be ineligible). The majority of the questionnaires were completed in English $(n=728)$ and were returned by mail $(n=714)$. Most of the participants were $>25$ years of age (91\%) (Table 1). More than half $(56 \%)$ of the respondents had a university degree or higher level of education, and most (80\%) spoke English at home. Just over half of the respondents indicated that they had more than one child at the time of the study (53\%) and a majority indicated that their youngest child was between the ages of 3 and 5 months (79\%), as expected on the basis of the sampling strategy. Obstetricians were most commonly mentioned as being the health-care professionals providing the majority of care during the most recent pregnancy (61\%) (Table 1).

\section{Experiences with NBS education}

Most participants (89\%) reported having heard of NBS, and $93 \%$ could recall their youngest child receiving screening; however, fewer (69\%) could recall ever receiving any specific information about NBS. Among respondents who reported having received information about NBS $(n=520)$, a majority recalled receiving this information after the birth of the infant, either just before the NBS test (62\%) and/or at the time of the heel prick test $(72 \%)$ (Table 2 ; these categories were not mutually exclusive). Nurses were the most common source of information about NBS (69\%), and books were mentioned as a source of information by some respondents (32\%) (Table 2). The most common methods of communication of NBS information, as recalled by the participants, were conversations with a healthcare professional (69\%) and the tear-off information sheet attached to the NBS blood-spot collection card (68\%). The
Table 1 Sample characteristics $(N=750)$

\begin{tabular}{|c|c|c|}
\hline & $n^{\text {a }}$ & $\%(95 \% \mathrm{Cl})$ \\
\hline \multicolumn{3}{|l|}{ Age (years) } \\
\hline$\leq 24$ & 69 & $9(7-12)$ \\
\hline $25-29$ & 176 & $24(21-27)$ \\
\hline $30-34$ & 298 & $40(37-45)$ \\
\hline$\geq 35$ & 205 & $27(24-31)$ \\
\hline \multicolumn{3}{|l|}{ Education } \\
\hline High school or less & 114 & $15(13-18)$ \\
\hline College & 213 & $29(25-32)$ \\
\hline University or higher & 409 & $56(52-59)$ \\
\hline \multicolumn{3}{|c|}{ Language most often spoken at home } \\
\hline English & 569 & $80(77-83)$ \\
\hline French & 20 & $3(2-4)$ \\
\hline English and French & 19 & $3(2-4)$ \\
\hline Other & 102 & $14(12-17)$ \\
\hline \multicolumn{3}{|l|}{ Marital status } \\
\hline Married or living with partner & 701 & $94(92-95)$ \\
\hline \multicolumn{3}{|l|}{ Parity } \\
\hline Primiparous & 352 & $47(43-51)$ \\
\hline Multiparous & 397 & $53(49-57)$ \\
\hline \multicolumn{3}{|l|}{ Age of youngest child (months) } \\
\hline$<3$ & 111 & $15(12-18)$ \\
\hline $3-<5$ & 589 & $79(76-82)$ \\
\hline$\geq 5$ & 47 & $6(5-8)$ \\
\hline \multicolumn{3}{|l|}{ Primary caregiver during pregnancy } \\
\hline Obstetrician & 439 & $61(57-65)$ \\
\hline Family physician & 126 & $18(15-21)$ \\
\hline Midwife & 110 & $15(13-18)$ \\
\hline Nurse & 33 & $5(3-6)$ \\
\hline
\end{tabular}

$\mathrm{Cl}$, confidence interval.

aNumbers may not add to the total sample size of 750 for each variable, due to item nonresponse.

latter was designed by Newborn Screening Ontario to be given to parents at the time of collection of the NBS sample. When asked to identify the content of educational information they had received, respondents most commonly recalled receiving information about the purpose of the NBS test (88\%), how the screening test is performed (85\%), and the importance of having their baby screened (72\%) (Table 2). Fewer than $15 \%$ of the participants recalled receiving information about how results would be stored or how the blood sample would be handled after testing (Table 2).

\section{Knowledge of content of key messages}

All the study participants were asked to respond to questions designed to ascertain their knowledge about NBS. Of those who completed these questions $(n=712)$, most were able to correctly identify the main purpose of NBS (82\%), were aware that the sample of blood should be taken at least $24 \mathrm{~h}$ after the 
Table 2 Experiences and satisfaction with newborn screening education among participants who recalled receiving information about newborn screening at any time $(n=520)$

\begin{tabular}{|c|c|c|}
\hline & $n^{\mathrm{a}}$ & $\%(95 \% \mathrm{Cl})$ \\
\hline \multicolumn{3}{|l|}{ Timing of NBS education } \\
\hline Before childbirth & 245 & $49(45-54)$ \\
\hline After childbirth, before the heel prick test & 309 & $62(58-67)$ \\
\hline At the time of the heel prick test & 355 & $72(67-76)$ \\
\hline After the heel prick test & 206 & $42(37-46)$ \\
\hline \multicolumn{3}{|l|}{ Commonly reported sources of NBS education } \\
\hline Nurses & 319 & $69(64-73)$ \\
\hline Books & 150 & $32(28-37)$ \\
\hline Prenatal class & 87 & $19(15-23)$ \\
\hline Obstetrician & 86 & $19(15-22)$ \\
\hline Midwife & 88 & $19(16-23)$ \\
\hline \multicolumn{3}{|c|}{ Commonly reported methods of communication about NBS } \\
\hline Conversation with a health-care professional & 344 & $69(65-73)$ \\
\hline $\begin{array}{l}\text { Information sheet given at the time of the } \\
\text { heel prick }\end{array}$ & 340 & $68(64-72)$ \\
\hline \multicolumn{3}{|c|}{ NBS information messages participants recalled receiving } \\
\hline The purpose of the newborn screening test & 436 & $88(85-91)$ \\
\hline The importance of having your baby screened & 354 & $72(68-76)$ \\
\hline How the screening process would be done & 419 & $85(81-88)$ \\
\hline $\begin{array}{l}\text { Whether you would be told about a negative } \\
\text { (normal) result }\end{array}$ & 236 & $48(43-52)$ \\
\hline $\begin{array}{l}\text { Whether you would be told about a positive } \\
\text { (abnormal) result }\end{array}$ & 264 & $53(49-58)$ \\
\hline $\begin{array}{l}\text { How you would be told if the result was } \\
\text { positive (abnormal) }\end{array}$ & 151 & $31(27-35)$ \\
\hline What a negative (normal) result means & 191 & $39(34-43)$ \\
\hline What a positive (abnormal) result means & 177 & $36(32-40)$ \\
\hline How the results would be stored & 38 & $8(6-10)$ \\
\hline $\begin{array}{l}\text { How the blood sample would be handled } \\
\text { after testing }\end{array}$ & 51 & $10(8-13)$ \\
\hline \multicolumn{3}{|c|}{ Participants' satisfaction with the education they received } \\
\hline Very satisfied & 96 & $19(16-23)$ \\
\hline Somewhat satisfied & 178 & $35(31-40)$ \\
\hline Neither satisfied nor dissatisfied & 107 & $21(18-25)$ \\
\hline Somewhat dissatisfied & 91 & $18(15-22)$ \\
\hline Very dissatisfied & 34 & $7(5-9)$ \\
\hline
\end{tabular}

$\mathrm{Cl}$, confidence interval; NBS, newborn blood-spot screening. ${ }^{a}$ Answers are not mutually exclusive, and there is some fluctuation in denominators used to calculate percentages, due to item nonresponse.

birth of the infant (75\%), and knew that a health-care provider would contact parents if an infant's NBS test results were positive (76\%) (Figure 1). However, only 35\% responded correctly to a true/false question to determine whether they knew that a positive (abnormal) screening result was possible even if an infant did not have a disease; more than half of the respondents (54\%) answered "don't know" to this question. Similarly, only $35 \%$ responded correctly to a question designed to test

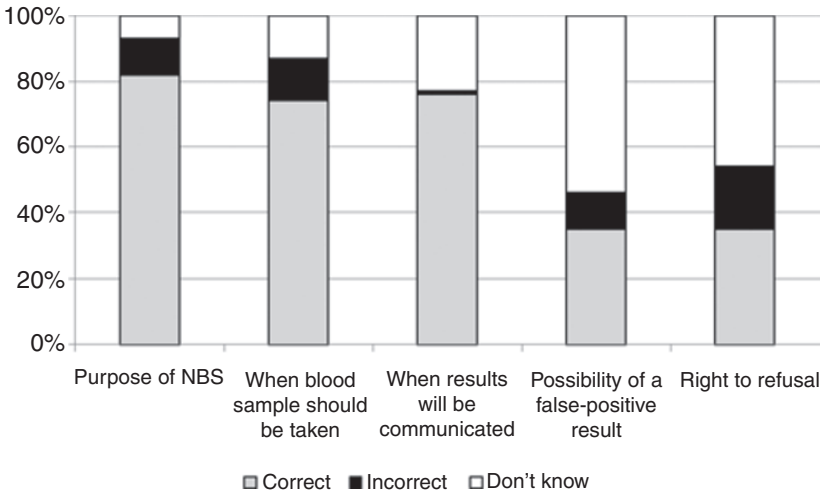

Figure 1 Participants' responses to knowledge questions about newborn screening $(\boldsymbol{n}=\mathbf{7 1 2})$. NBS, newborn blood-spot screening.

whether they were aware that parents have the choice not to have their infant undergo NBS; many mothers responded "don't know" (46\%) (Figure 1). As we had anticipated, the latter question was associated with participants recalling having received information about NBS (odds ratio $(\mathrm{OR})=2.5, P<0.01$, data not shown). Using a cutoff of $4 / 5$ correct answers, $37 \%$ of the participants were considered to have "high knowledge."

\section{Satisfaction with NBS education}

Participants who recalled receiving any information about NBS $(n=520)$ were asked to indicate their level of satisfaction with the information received. Among those who responded $(n=506)$, there was considerable variability in reported satisfaction, with more than half of them reporting being "very" $(19 \%)$ or "somewhat" (35\%) satisfied, and one-quarter of them reporting being "very" (7\%) or "somewhat" (18\%) dissatisfied (Table 2).

\section{Factors associated with having high knowledge}

In the bivariate analysis, participants who were more likely to have high knowledge were those with a post-secondary education or higher as compared with those with a high school education or lower (college, $\mathrm{OR}=1.79$; university or higher, $\mathrm{OR}=2.43$ ), those who recalled receiving any information about NBS $(\mathrm{OR}=3.18)$, and those who received information prenatally $(\mathrm{OR}=1.58)$, from a health-care professional $(\mathrm{OR}=$ 2.09), or from the tear-off information sheet given at the time of the blood sample collection $(\mathrm{OR}=1.98)$ (Table 3, bivariate results). Respondents were also more likely to have high knowledge if they recalled receiving information about the purpose of screening $(\mathrm{OR}=2.70)$, how screening would be done $(\mathrm{OR}=$ $2.57)$, how results would be communicated $(\mathrm{OR}=1.98)$, and the meaning of negative or positive results $(\mathrm{OR}=2.64)$ (Table 3$)$.

In the full-sample multivariate model, having high knowledge was significantly associated with having a post-secondary education (college, $\mathrm{OR}=1.89$; university or higher, $\mathrm{OR}=$ 2.67) and having recollection of receiving information about NBS (OR = 3.13) (Table 3, model 1). Among participants who reported having received information about NBS at any time, independent predictors of having high knowledge 
Table 3 Variables associated with having high knowledge about NBS

\begin{tabular}{|c|c|c|c|}
\hline & Bivariate results & Knowledge model $1^{\text {a }}$ & Knowledge model $2^{\mathrm{b}}$ \\
\hline & OR $(95 \% \mathrm{Cl})$ & OR $(95 \% \mathrm{Cl})$ & OR $(95 \% \mathrm{Cl})$ \\
\hline \multicolumn{4}{|l|}{ Age (years) } \\
\hline $25-29$ & $1.57(0.83-2.98)$ & NS & NS \\
\hline $30-34$ & $1.80(0.98-3.29)$ & NS & NS \\
\hline High school or less & Reference & Reference & Reference \\
\hline College & $1.79(1.05-3.08)^{\star}$ & $1.89(1.06-3.34)$ & $1.89(0.97-3.66)$ \\
\hline University or higher & $2.43(1.48-3.99)^{* *}$ & $2.67(1.57-4.53)$ & $2.79(1.51-5.17)$ \\
\hline \multicolumn{4}{|l|}{ Language spoken most often at home } \\
\hline \multicolumn{4}{|l|}{ Recalled receiving information from: } \\
\hline Health-care professional & $2.09(1.19-3.65)^{* *, c}$ & $\mathrm{n} / \mathrm{a}$ & NS \\
\hline Tear-off sheet given at sample collection & $1.98(1.32-2.97)^{* *, c}$ & $\mathrm{n} / \mathrm{a}$ & $1.57(1.01-2.43)^{c}$ \\
\hline Received information prenatally & $1.58(1.10-2.27)^{\star, c}$ & $\mathrm{n} / \mathrm{a}$ & NS \\
\hline \multicolumn{4}{|l|}{ Received information about: } \\
\hline Purpose of screening & $2.70(1.37-5.33)^{* *, c}$ & $\mathrm{n} / \mathrm{a}$ & NS \\
\hline How screening would be done & $2.57(1.47-4.50) * * . c$ & $\mathrm{n} / \mathrm{a}$ & NS \\
\hline How results will be communicated & $1.98(1.36-2.88)^{* *, c}$ & $\mathrm{n} / \mathrm{a}$ & NS \\
\hline Meaning of positive and negative results & $2.64(1.81-3.84)^{* *, c}$ & $\mathrm{n} / \mathrm{a}$ & $2.65(1.76-3.99)^{c}$ \\
\hline
\end{tabular}

$\mathrm{Cl}$, confidence interval; n/a, not applicable; NBS, newborn blood-spot screening; NS, not a significant predictor; OR, odds ratio.

${ }^{a}$ Results based on full sample. ${ }^{b}$ Results based on mothers who reported having received information. 'Odds ratios are compared with mothers who responded "No" or "Don't know" to questions about information received. ${ }^{*} P<0.05 ;{ }^{*} P<0.01$.

included having a post-secondary education (college, OR = 1.89 ; university or higher, $\mathrm{OR}=2.79$ ), reporting English as the language most often spoken at home $(\mathrm{OR}=1.96)$, receiving information through a tear-off sheet given at the time of the blood sample collection $(\mathrm{OR}=1.57)$, and receiving information about the meaning of positive/negative results $(\mathrm{OR}=2.65)($ Table 3 , model 2).

\section{Factors associated with being satisfied with information received}

In bivariate analysis, participants were more likely to report being "very" or "somewhat" satisfied with the information they received if they recalled receiving information prenatally $(\mathrm{OR}=2.37)$, from a health-care professional $(\mathrm{OR}=5.81)$, or from the tear-off sheet given at the time of the collection of the blood sample $(\mathrm{OR}=2.21)$ (Table 4, bivariate results). Respondents were also more likely to report being satisfied if they recalled receiving information about the purpose of screening $(\mathrm{OR}=11.33)$, how screening would be done (OR $=6.15)$, how results would be communicated $(\mathrm{OR}=5.53)$, the meaning of positive and negative results $(\mathrm{OR}=8.91)$, and information on the storage and handling of the sample (OR = 8.04) (Table 4).

In the multivariate model, final significant predictors of being satisfied with NBS education included receiving information prenatally $(\mathrm{OR}=2.35)$, from a health-care professional $(\mathrm{OR}=$ 4.54), and from the tear-off sheet given at the time of the heel prick $(\mathrm{OR}=1.72)$ (Table 4, multivariable results). Being satisfied was also significantly associated with receiving information about the purpose and benefits of screening $(\mathrm{OR}=3.78)$, how results would be communicated ( $\mathrm{OR}=2.57)$, the meaning of positive and negative results $(\mathrm{OR}=4.19)$, and information about storage and handling of the sample $(\mathrm{OR}=3.13)($ Table 4$)$.

\section{Mothers' awareness of NBS}

\section{DISCUSSION}

When asked about their experiences with NBS, most participants in our study reported having heard of NBS and could recall their youngest child receiving NBS. Whereas similar findings were reported by Davey et al..$^{20}$ (93\% of mothers reported having heard of NBS), other studies have reported lower awareness of NBS among parents. ${ }^{1,2}$ This apparent high awareness of 
Table 4 Variables associated with being satisfied with NBS education

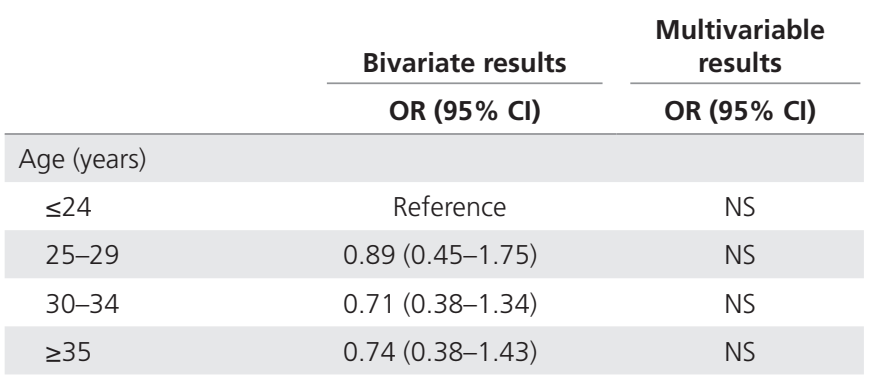

Education

High school or less $\quad$ Reference

College

$0.98(0.56-1.73)$

NS

University or higher

$0.75(0.45-1.26)$

NS

NS

Language

$\begin{array}{lcc}\text { English } & \text { Reference } & \text { NS } \\ \text { Other } & 0.85(0.52-1.40) & \text { NS }\end{array}$

Recalled receiving information from:

$\begin{array}{lcc}\begin{array}{l}\text { Health-care } \\ \text { professional }\end{array} & 5.81(3.07-10.98)^{*, \mathrm{a}} & 4.54(2.03-10.15)^{\mathrm{a}} \\ \begin{array}{l}\text { Tear-off sheet given } \\ \text { at sample collection }\end{array} & 2.21(1.51-3.25)^{\star, \mathrm{a}} & 1.72(1.04-2.83)^{\mathrm{a}} \\ \begin{array}{l}\text { Received information } \\ \text { prenatally }\end{array} & 2.37(1.66-3.40)^{\star, \mathrm{a}} & 2.35(1.48-3.75)^{\mathrm{a}}\end{array}$

Received information about:

\begin{tabular}{lcc}
$\begin{array}{l}\text { Purpose of } \\
\text { screening }\end{array}$ & $11.33(4.39-29.23)^{*, \mathrm{a}}$ & $3.78(1.30-11.05)^{\mathrm{a}}$ \\
$\begin{array}{l}\text { How screening } \\
\text { would be done }\end{array}$ & $6.15(3.33-11.39)^{*, \mathrm{a}}$ & NS \\
$\begin{array}{l}\text { How results will be } \\
\text { communicated }\end{array}$ & $5.53(3.74-8.19)^{\star, \mathrm{a}}$ & $2.57(1.57-4.21)^{\mathrm{a}}$ \\
$\begin{array}{l}\text { Meaning of positive } \\
\text { and negative results }\end{array}$ & $8.91(5.79-13.70)^{*, \mathrm{a}}$ & $4.19(2.52-6.99)^{\mathrm{a}}$ \\
$\begin{array}{l}\text { Information on } \\
\text { use/storage of sample }\end{array}$ & $8.04(3.58-18.06)^{*, \mathrm{a}}$ & $3.13(1.15-8.53)^{\mathrm{a}}$ \\
\hline
\end{tabular}

$\mathrm{Cl}$, confidence interval; NBS, newborn blood-spot screening; NS, not a significant predictor; OR, odds ratio.

aOdds ratios are compared with mothers who responded "No" or "Don't know" to questions about information received. All of these questions were separate and are therefore not mutually exclusive (e.g., mothers could report receiving information from both a health-care professional and the tear-off sheet). ${ }^{*} P<0.01$.

NBS among mothers of infants in Ontario should be interpreted with caution because nonresponse bias is likely to have played some role in our findings: our response rate of $47 \%$ was typical for surveys of this nature, ${ }^{21}$ but it is possible to hypothesize that mothers who chose to participate had a greater awareness of NBS than nonresponders did.

\section{Mothers' experiences with education about NBS}

Despite this high level of awareness of NBS, $<70 \%$ of the participants reported actually receiving any information about NBS at any time. In Ontario, NBS is considered to be the standard of care and, as mentioned earlier, it is implemented by default unless there is any specific parental objection. If there is no direct expectation for parental involvement in decision making about NBS, one might question whether concerns might be misplaced about this apparent lack of education for a substantial minority of parents. We have highlighted that one argument for ensuring effective parental pre-screening education about NBS is to maximize the benefits of NBS (educating parents about the purpose, benefits, and process of screening may improve follow-up rates) ${ }^{8}$ and to mitigate its potential psychosocial harms (educating parents about the possibility of receiving a positive result even for an infant who has no disease may help to prepare them for such results). ${ }^{9,10}$ More broadly, though, there is also some evidence that parents wish to be informed about NBS. ${ }^{1,20}$ That parents have an expectation to be provided with education about NBS is in line with the more general assertion by Manson ${ }^{22}$ that patients often want information about interventions, independent of their desire to take part in decision making about those interventions. Such information may be expected by patients from their caregivers so that they can prepare for other decisions that may follow, or simply as a sign of respect and a means of fostering trust. This issue is connected to the aforementioned notion of communication as a means of protecting public confidence in NBS.

In short, effective NBS education practices may be important not only because parents need the knowledge to achieve the benefits and minimize the harms of screening, but also because they expect to receive such information, and it contributes to their satisfaction with, and trust in, the screening program. This suggests that both parental knowledge and parental satisfaction are important outcomes in evaluating NBS education. Our results help to clarify which aspects of NBS education are the ones most strongly associated with these outcomes among mothers in Ontario, focusing on strategies for both delivery of information (when, who, in what format) and content (specific messages). Interestingly, in our study, the satisfaction outcome appeared to be more sensitive to differences in the delivery and content of the educational messages than the knowledge outcome was, as judged by the number of independent predictors and the strength of the associations. We must point out, however, that we ascertained satisfaction with NBS education only among those who recalled receiving such education (because we were interested in understanding the specific elements of education that were important predictors of satisfaction); therefore, our descriptive findings are likely to be an overestimate of the overall satisfaction levels in the population.

\section{Delivery of NBS education}

Among mothers who could recall receiving any information about NBS, a higher proportion reported receiving information during the postnatal period, rather than prenatally. This concurs with the findings of other studies, and, as mentioned earlier, is a practice that is contrary both to empirical evidence and to published recommendations that highlight the prenatal period as the preferred time for parental education about NBS. ${ }^{1,3-6}$ In our 
study, receipt of information prenatally was not independently associated with higher knowledge about NBS, but was significantly associated with higher satisfaction. Receiving information from a health-care provider was also significantly associated with higher satisfaction, although not with higher knowledge. Therefore, although there are important barriers to engaging prenatal care providers in the process of NBS education, ${ }^{7}$ our findings provide empirical support for the assertion that this is a key priority if meeting parental expectations (and not just improving their knowledge) is a goal.

The most common source of information about NBS as reported by our study participants was nursing staff, whereas the most common methods of receiving information were through a conversation with a health-care provider and from an information sheet given at the time of blood sample collection. These findings reflect the fact that, currently, the timing of education about NBS in Ontario and many other jurisdictions is postnatal rather than prenatal. Education is being received by mothers mainly at the time of the collection of the blood sample from the infant, when there is likely to be a natural conversation about NBS as part of the health-care provider's interaction with the family while handling the newborn for the heel prick. This suggests that many parents may be "passive receivers" (rather than active seekers) of information about NBS, ${ }^{23}$ becoming aware of screening only when their baby's blood is being sampled. This is perhaps a consequence of the routine approach to NBS in Ontario and elsewhere (i.e., without requiring explicit informed consent from parents). It would be interesting to explore, in future research, whether the provision of education during the prenatal period would lead to an increase in active informationseeking about NBS among prospective parents, and whether this, in turn, would lead to greater knowledge or satisfaction. In the meantime, the receipt of education through the information sheet given at the time of the blood sample collection was the most prominent aspect of NBS education delivery that was associated with both higher knowledge and with satisfaction as per our study analysis. Together with the finding that receiving information through a conversation with a health-care provider was a key determinant of the participants' levels of satisfaction, the results highlight the importance of supporting postpartum nurses in their current role as NBS educators.

\section{Content of NBS education}

A high proportion of the mothers in our study recalled receiving information about the purpose and importance of screening. This concurs with recent US guidelines about the content of NBS education, ${ }^{1}$ and with previous studies, which found that written educational materials have tended to emphasize the purpose and benefits of NBS more than other elements. ${ }^{24-26}$ Study participants were significantly more likely to report being satisfied if they recalled receiving information about the purpose of screening. This supports the importance of including this aspect in the educational content, although there was no significant independent association between this aspect and improvement in the participants' knowledge of NBS. A lower proportion of study participants recalled receiving information about how NBS results are communicated, and this information too was associated with higher satisfaction. Similarly, only a modest proportion of participants recalled being informed about the meaning of positive and negative results, and only one-third of the participants correctly answered the knowledge question that identified the possibility of a false-positive result. Despite this, receiving information about the meaning of positive and negative results was a predictor of both higher knowledge and higher satisfaction. These findings suggest that messages about both the meaning of the results and how they are communicated may deserve further emphasis in NBS education for parents in Ontario, to promote knowledge and to meet parents' expectations. Finally, receipt of information about how the NBS sample would be stored and handled was independently associated with satisfaction among the study participants, despite only one-tenth of them recalling having received such information. The issue of appropriate stewardship of NBS dried blood-spot samples has recently gained traction in the public sphere as well as in the scientific literature. ${ }^{11-13,27,28}$ Although these issues were not fully explored in our study, they are connected with notions of transparency and trust. Therefore, in addition to exploring the impact of increasing the provision of education about NBS to prospective parents during the prenatal period, an important research priority is to investigate the ways in which information about the storage and potential secondary uses of NBS blood spots can best be communicated to both parents and the public.

\section{Conclusions}

Effective pre-screening education is an important component of the NBS system. Informing parents about the purpose, benefits, process, and possible results of screening may facilitate prompt follow-up after an initial positive result, and may mitigate potential psychosocial harm. Effective education may also be a valuable tool to enhance parental trust in the NBS program and to promote a positive experience with NBS. Our findings suggest that promoting satisfaction with NBS education among mothers in Ontario may require greater attention to the prenatal period, and that the emphasis may best be placed on education through conversations with health-care providers. While the results support a continued focus on the purpose of screening as an important message for parents, greater attention to the communication process and to the methods of storage and use of NBS samples may further promote parental satisfaction. An emphasis on messages conveying the meaning of both positive and negative results may help to foster both satisfaction and knowledge.

\section{ACKNOWLEDGMENTS}

This study was supported by internal research funds from the University of Ottawa (B.K.P.).

\section{DISCLOSURE}

The authors declare no conflict of interest. 


\section{REFERENCES}

1. Davis TC, Humiston SG, Arnold CL, et al. Recommendations for effective newborn screening communication: results of focus groups with parents, providers, and experts. Pediatrics 2006;117(5 Pt 2):S326-S340.

2. Suriadi C, Jovanovska M, Quinlivan JA. Factors affecting mothers' knowledge of genetic screening. Aust N Z J Obstet Gynaecol 2004;44:30-34

3. Clayton EW. Talking with parents before newborn screening. J Pediatr 2005;147(3 suppl):S26-S29.

4. Campbell ED, Ross LF. Incorporating newborn screening into prenatal care. Am J Obstet Gynecol 2004;190:876-877.

5. Detmar S, Hosli E, Dijkstra N, Nijsingh N, Rijnders M, Verweij M. Information and informed consent for neonatal screening: opinions and preferences of parents. Birth 2007;34:238-244.

6. Tluczek A, Orland KM, Nick SW, Brown RL. Newborn screening: an appeal for improved parent education. J Perinat Neonatal Nurs 2009;23: 326-334.

7. Hayeems RZ, Miller FA, Little J, et al. Informing parents about expanded newborn screening: influences on provider involvement. Pediatrics 2009;124:950-958.

8. Kemper AR, Fant KE, Clark SJ. Informing parents about newborn screening. Public Health Nurs 2005;22:332-338.

9. Gurian EA, Kinnamon DD, Henry JJ, Waisbren SE. Expanded newborn screening for biochemical disorders: the effect of a false-positive result. Pediatrics 2006;117:1915-1921.

10. Hewlett J, Waisbren SE. A review of the psychosocial effects of false-positive results on parents and current communication practices in newborn screening. J Inherit Metab Dis 2006;29:677-682.

11. Couzin-Frankel J. Newborn blood collections. Science gold mine, ethical minefield. Science 2009;324:166-168.

12. Lewis MH, Goldenberg A, Anderson R, Rothwell E, Botkin J. State laws regarding the retention and use of residual newborn screening blood samples. Pediatrics 2011;127:703-712.

13. Trinidad SB, Fullerton SM, Ludman EJ, Jarvik GP, Larson EB, Burke W. Research ethics. Research practice and participant preferences: the growing gulf. Science 2011;331:287-288.

14. Larson HJ, Cooper LZ, Eskola J, Katz SL, Ratzan S. Addressing the vaccine confidence gap. Lancet 2011;378:526-535.

15. American College of Obstetricians and Gynecologists Committee on Genetics. Committee opinion no. 481: newborn screening. Obstet Gynecol 2011;117: $762-765$.
16. Newborn screening: toward a uniform screening panel and system. Genet Med 2006;8(suppl 1):1S-252S.

17. American Academy of Pediatrics Newborn Screening Task Force. Serving the family from birth to the medical home. Newborn screening: a blueprint for the future - a call for a national agenda on state newborn screening programs. Pediatrics 2000;106:389-427.

18. Hargreaves KM, Stewart RJ, Oliver SR. Informed choice and public health screening for children: the case of blood spot screening. Health Expect 2005:8:161-171.

19. Dillman DA. Mail and Internet Surveys: The Tailored Design Method, 2nd edn John Wiley \& Sons Inc.: Hoboken NJ, 2000

20. Davey A, French D, Dawkins H, O'Leary P. New mothers' awareness of newborn screening, and their attitutdes to the retention and use of screening samples for research purposes. Genom Soc Pol 2005;1:41-51.

21. Baruch $Y$, Holtom $B C$. Survey response rate levels and trends in organizational research. Hum Relat 2008;61:1139-1160.

22. Manson NC. Why do patients want information if not to take part in decision making? J Med Ethics 2010;36:834-837.

23. Nicholls SG, Southern KW. Parental information use in the context of newborn bloodspot screening. An exploratory mixed methods study. J Community Genet 2012; e-pub ahead of print 16 February 2012.

24. Araia MH, Potter BK. Newborn screening education on the internet: a content analysis of North American newborn screening program websites. J Community Genet 2011;2:127-134

25. Fant KE, Clark SJ, Kemper AR. Completeness and complexity of information available to parents from newborn-screening programs. Pediatrics 2005;115:1268-1272.

26. Hargreaves K, Stewart R, Oliver S. Newborn screening information supports public health more than informed choice. Health Educ J 2005;64:110-119.

27. Botkin JR, Rothwell E, Anderson R, et al. Public attitudes regarding the use of residual newborn screening specimens for research. Pediatrics 2012;129:231-238.

28. Bombard $Y$, Miller FA, Hayeems RZ, et al. Citizens' values regarding research with stored samples from newborn screening in Canada. Pediatrics 2012;129:239-247

(c) This work is licensed under the Creative Commons Attribution-Noncommercial-No Derivative Works 3.0 Unported License. To view a copy of this license, visit http://creativecommons.org/ licenses/by-nc-nd/3.0/ 